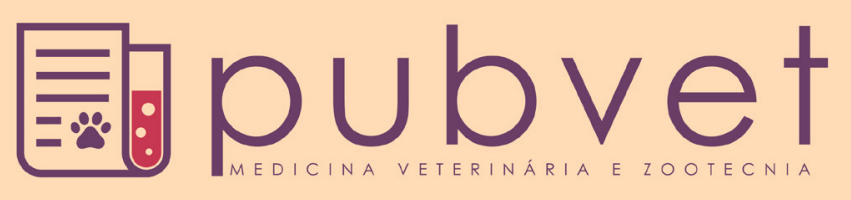

HTTP://DX.DOI.ORG/10.22256/PUBVET.V11N8.793-801

\title{
Quimioterapia metronômica para o tratamento de tumor de células carcinomatosas de transição na região de trígono vesical em gato: Relato de caso
}

Filipe Zanella Grapegia ${ }^{*}$, Bruno Roque Lima²

${ }^{\text {I} A l u n o ~ d e ~ P o ́ s-G r a d u a c ̧ a ̃ o ~ e m ~ C l i ́ n i c a ~ M e ́ d i c a ~ e ~ C i r u ́ r g i c a ~ e m ~ P e q u e n o s ~ A n i m a i s ~ d a ~ U n i v e r s i d a d e ~ C a m i l o ~ C a s t e l o ~ B r a n c o, ~ C a s c a v e l . ~}$

${ }^{2}$ Professor da Universidade Camilo Castelo Branco, Cascavel.*Autor para correspondência,E-mail: filipegrapegia@hotmail.com

RESUMO. A quimioterapia metronômica vem ganhando espaço na medicina veterinária graças a sua facilidade em realizar o tratamento e o seu baixo custo, assim os proprietários estão aceitando com mais facilidade em submeter os seus animais a esse tratamento. Outra vantagem da metronômica em relação a quimioterapia com dose máxima tolerada é os seus efeitos colaterais serem mais brandos. A escolha do tipo de tratamento quimioterápico depende do estado geral do paciente e dos critérios adotados pelo Médico Veterinário. $\mathrm{O}$ presente trabalho teve como objetivo mostrar os resultados do tratamento com a quimioterapia metronômica em um gato, diagnosticado com carcinoma de células de transição na região de trígono vesical, sem expor o animal a uma cirurgia para retirada de amostra para a realização do exame histopatológico. O foco desse tratamento consiste na melhoria da qualidade de vida do paciente e conseguir curar ou controlar a sua doença.

Palavras chave: Quimioterapia, metronômica, carcinoma, gato

\section{Metronomic chemotherapy for treatment of tumor of transition carcinomatosis cells in the region of vesical trigon in cate: Case report}

\begin{abstract}
The metronomic chemotherapy has been winning space on Veterinary Medicine gracefulness to it easiness accomplish of the treatment and it's low price, so the owners are accepting facility to submit your pet to this treatment. The other advantage of metronomic than conventional chemotrerapy is their colateral effects are lighter. The choice of the type of chemotherapy treatment depends on the general condition of the patient and the criterion adopted by the veterinarian. The present work had as objective to show results of treatment with metronomic chemotherapy in cat, diagnosed with carcinoma of transitional cell in the region of vesical trigon, without exposing the animal to a surgical procedure directed to remove a tissue sample for a histopathological examination. The focus of this treatment was the improvements of patient's life quality and achieves to fully heal or control the disease.
\end{abstract}

Keyword: Chemotherapy, metronomic, carcinoma, cat

\section{Quimioterapia metronómica para el tratamiento de tumor de células carcinomatosas de transición en la región de trígono vesical en gato: Reporte de caso}

RESUMEN. La quimioterapia metronómica viene ganando espacio en la medicina veterinaria gracias a su facilidad en realizar el tratamiento y su bajo costo, así los propietarios están aceptando con más facilidad en someter a sus animales a ese tratamiento. Otra ventaja de la metronómica en relación a la quimioterapia con dosis máxima tolerada 
es que sus efectos secundarios sean más suaves. La elección del tipo de tratamiento quimioterápico depende del estado general del paciente y de los criterios adoptados por el Médico Veterinario. El presente trabajo tuvo como objetivo mostrar los resultados del tratamiento con la quimioterapia metronómica en un gato, diagnosticado con carcinoma de células de transición en la región de trígono vesical, sin exponer al animal a una cirugía para retirar la muestra para la realización del examen histopatológico. El foco de este tratamiento consiste en mejorar la calidad de vida del paciente y conseguir curar o controlar su enfermedad.

Palabras clave: Quimioterapia, metrónomo, carcinoma, gato

\section{Introdução}

A oncologia veterinária tem evoluído consideravelmente nas últimas décadas, proporcionando tratamentos mais eficazes e com mais alternativas para os pacientes, encontrando diferentes tipos de antineoplásicos. O tratamento oncológico veterinário consiste no tratamento de neoplasias hematopoiéticas, em terapias adjuvantes para o controle de micro metástase em potencial, na prevenção de recidivas de tumores sólidos e no tratamento paliativo de tumores irressecáveis ou metastáticos (Barros and Repetti, 2015). A predominância do câncer vem aumentando na medicina veterinária nos últimos anos, justamente pelo desenvolvimento da medicina preventiva e do aumento da longevidade dos animais. Essas enfermidades são consideradas como o a maior frequência de mortes em cães no Brasil, e a incidência é maior em pacientes geriátricos (Martins et al., 2011). A quimioterapia é um tratamento definido pela aplicação de fármacos para destruir ou inibir células cancerígenas, vírus ou bactéria no organismo. É um tratamento bastante comum na medicina veterinária e a sua utilização deve ser feita através de diagnósticos corretos, estadiamento da doença e o estado geral do animal (Silveira, 2016).

\section{Revisão de Literatura}

A quimioterapia convencional funciona utilizando a dose máxima tolerada pelo paciente, onde é definida como a dose que representa resposta mediana à moderada diante uma toxicidade considerada severa em apenas 5\% dos animais saudáveis. Os fármacos que são utilizados hoje em dia são adquiridos e adaptados com base da experiência da oncologia humana (Steffenon, 2014). O tratamento convencional pode apresentar vários efeitos colaterais como toxicidade elevada, desenvolvimento de resistências aos citostáticos e falta de especificidade, responsável por diversos efeitos secundários e por períodos de pausa obrigatórios entre tratamentos (Khosravi and Pérez, 2007). Quimioterapia convencional baseia- se na utilização da dose máxima tolerada (DMT) que é considerada como não especifica podendo provocar danos e toxicidade em tecidos neoplásicos e sadios como, por exemplo, medula óssea e epitélio intestinal, pois esses fármacos atuam em células de rápida divisão mitótica. Por causa dos efeitos colaterais que esse tratamento se institui é feita com a dose máxima que o paciente consiga tolerar e com intervalos longos para observar como o organismo do paciente vai reagir aos efeitos secundários e se necessários precise de um tratamento de suporte (Barros and Repetti, 2015).

A DMT visa administrar a dose máxima do fármaco que um organismo possa tolerar, sabendo dos efeitos adversos podem ser lesivas as doses utilizadas na medicina veterinária acabam sendo menores do que as utilizadas na oncologia da medicina humana. Já se esperando a toxidade, os ciclos de aplicações variam de 3 a 4 semanas ou mais de duração, justamente para dar tempo aos tecidos do epitélio intestinal e a medula óssea a se recuperarem para a próxima aplicação (Mendes, 2014). O motivo de se trabalhar com a DMT é que a morte celular, das células cancerígenas, aumenta com a concentração de quimioterápico utilizado, assim quanto mais droga administrada, maior é a chance de erradicar o tumor. O que define o limite do fármaco usado é sua toxicidades em tecidos normais, em razão das células que são mais afetadas são as de rápida divisão mitótica. Por causa dessa toxicidade que se faz o uso de um tempo prolongado, para que o organismo possa de recuperar, juntamente com tratamento de suporte, como protetores gastrointestinais, medicações anti-eméticas, fatores de crescimento hematopoiéticos e o transplante de medula (Johnson and Wisner, 2007).

Quimioterápicos citotóxicos convencionais causam danos diretos ao DNA celular durante o seu ciclo de divisão celular para destruir o máximo possível de células. O mecanismo de ação dos fármacos não está exclusivamente associado com 
a destruição celular, mas também no processo de inibição da angiogênese, que é o processo de crescimento de novos vamos sanguíneos para a nutrição do tumor (Mendes, 2014). A principal ação é na divisão celular, desde a replicação do Ácido Desoxirribonucleico (DNA) (fase $\mathrm{S}$ do ciclo celular) à subsequente divisão celular ou mitose (fase $\mathrm{M}$ do ciclo celular), ou também nas fases de replicação do Ácido Ribonucleico (RNA) e de proteínas (fase G1 e G2 do ciclo celular). Também as células podem interromper o ciclo celular durante a fase de repouso G0, na qual podem não ser tão susceptíveis aos fármacos (Silveira, 2016).

Os efeitos secundários em análise foram a toxicidade hematopoiética, gastrointestinal, dermatológica e pulmonar, reações alérgicas/ anafiláticas, cistite hemorrágica estéril, necrose perivascular/extravasamento, cardiotoxicidade, nefrotoxicidade, hepatotoxicidade, neurotoxicidade e síndrome de lise tumoral aguda (Cunha, 2014). Os efeitos secundários mais frequentes acabam estão relacionados aos tecidos com maior índice mitótico, como a medula óssea e o aparelho GI (Osborne et al., 1999). Mas também são descritos efeitos secundários dermatológicos, cardiotoxicidade, nefrotoxicidade, neurotoxicidade, reações de hipersensibilidade, extravasamento/necrose perivascular, toxicidade pulmonar, hepatotoxicidade, síndrome de lise tumoral aguda, cistite hemorrágica estéril, pancreatite, entre outros sinais gerais como prostração, depressão e apatia. Estes efeitos secundários podem ser agudos ou crônicos, podendo durar meses (Cunha, 2014).

Toxicidade secundária é um fator importante na hora da decisão dos intervalos dos ciclos de tratamento. Cada quimioterápico tem um nadir específico que coincide com o valor máximo de mielossupressão, para a maioria dos fármacos, este momento ocorre entre sete a dez dias após a administração, observando-se uma recuperação ao vigésimo primeiro dia. No entanto, o intervalo deve ser o mínimo possível, inibindo a expansão da população tumoral (Silveira, 2016).

A quimioterapia metronômica oferece um novo conceito no tratamento do câncer, além de um protocolo citotóxico diferente do convencional. Quimioterapia Metronómica consiste na terapia constante com quimioterápicos, contrário da quimioterápica convencional, que o tratamento é realizado com doses altas em datas pré-programadas. A metronômica se faz no tratamento diário utilizando doses mínimas por um período longo de tempo (Khosravi and Pérez, 2007, Penter, 2013).

A terapia metronómica também vem mostrando resultado que é capaz de controlar a resistência quimioterápica tem efeitos aceitáveis quando é combinada com agentes antiangiogênicos e consegue controlar o crescimento tumoral. Na medicina veterinária tem sido vista com bons olhos graça ao seu baixocusto, comodidade e os efeitos adversos serem mais brandos (Mendes, 2014). Tendo um comparativo das duas maneiras de quimioterapia, a metronômica baseia-se nas doses na administração frequente de fármacos citostáticos em doses baixas e não necessitando de pausas prolongadas entre as administrações. Assim tendo um baixo nível de concentração sanguínea e efeitos colaterais pouco significativos e melhorando a eficácia antitumeral pela inibição da angiogênese no sitio do tumor (Cabral, 2013, Reis, $\underline{2010)}$.

Com base em todos os eventuais eventos prejudiciais da quimioterapia convencional surgiu a quimioterapia metronômica, que se baseia na administração contínua de agentes quimioterápicos em doses relativamente baixas, com toxicidade mínima e com intervalos mínimos entre tratamentos (Khosravi and Pérez, 2007). O princípio de ação deduz uma contínua exposição das células tumorais sensíveis ao fármaco, alterações na imunologia tumoral e atuação nas células endoteliais vasculares tumorais que estão em multiplicação, combatendo a angiogénese e obtendo-se assim o efeito anti-neoplásico pretendido (Cunha, 2014). O seu mecanismo de ação não está exclusivamente nas células neoplásicas, mas também em nível da angiogênese tumoral. A quimioterapia metronómica parece impulsionar importantes efeitos antiangiogénicos (inibição da proliferação; migração e morfogénese das células endoteliais, diminuição da viabilidade das células progenitoras endoteliais (CEPs) e aumento da expressão de trombospondina-1 (TSP1)), levando a uma redução da irrigação sanguínea do tumor (Pasquier et al., 2010). Tumor que tem um crescimento progressivo e metastático tem poderes de realizar a angiogênese. A contínua administração de quimioterápicos tem se mostrado eficaz no controle da angiogênese tumoral (Barros and Repetti, 2015). São várias as vantagens da quimioterapia metronómica sobre a convencional: Atividade contra o parênquima e estroma, componentes da neoplasia; Maior 
atividade pró-apoptótica e antiangiogénica; Grande estabilidade genética das células endoteliais normais em relação às diversas alterações genéticas características das células tumorais que levam à resistência ao fármaco; Menor probabilidade de aparecimento de quimioresistências adquiridas, pela relativa falta de capacidade das células endoteliais não transformadas para desenvolver resistência aos quimioterápicos; Menores efeitos secundários sistêmicos e menor toxicidade aguda; Administração a longo termo mais viável; Utilização de fármacos já conhecidos, com menores custos e maior facilidade de aplicação; Possibilidade de combinação com outros citostáticos, com fármacos antiangiogénicos e também tratamentos com alvos moleculares. Administração por via oral, fora do ambiente hospitalar, as desvantagens limitam-se ao fato da dose dos quimioterápicos e associação com outros fármacos serem calculadas empiricamente (Khosravi and Pérez, 2007).

Existem poucos estudos que avaliam a toxicidade da quimioterapia metronômica, mas mesmo assim, muitos autores afirmam que a toxidades da quimioterapia convencional é maior do que a quimioterapia metronômica (García et al., 2009). Os rins estão fortemente envolvidos na eliminação de vários fármacos e seus metabolitos, quer através da filtração glomerular. Eles são potencialmente sensíveis aos efeitos tóxicos dos quimioterápicos, mais comum em compostos platinados, como cisplatina para cão e doxorrubicina para gatos (Silveira, 2016). A ciclofosfamida pode trazer efeitos tóxicos como, leucopenia, êmese, diarreia e anorexia. Esses distúrbios podem acontecer devido à ação citostática inespecífica da ciclofosfamida (Faro et al., 2009).

Um estudo feito com 12 gatos sendo tratados com ciclofosfamida em doses metronômicas foi encontrado níveis de nefrotoxidade num porcentual de $4 \%$, nas primeiras 4 semanas, e de $12 \%$, após 2 meses de tratamentos. Para controle e cuidados dessa possível nefrotoxidade é necessária a realização periódica de exames de urianálise e quantificação de creatinina e ureia plasmática (Silveira, 2016). No mercado existe uma grande variedade de fármacos quimioterápicos, com diversos mecanismos de ação, formas de toxicidade e características próprias. Estes podem ser não específicos do ciclo-celular ou específicos de uma fase do ciclo

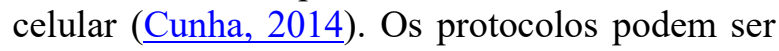

usados utilizando apenas um fármaco ou associar outras drogas, tudo depende da situação da doença que o paciente apresenta, qual é a neoplasia que está afetando o seu organismo e como ela age. Os antineoplasicos são distribuídos em várias classes: Compostos alquilantes (ciclofosfamida, clorambucil, melfalan, ifosfamida, lomustina, dacarbazina), compostos antimetabólicos (metotrexato, 5-flurouracil, citarabina), antibióticos antineoplásicos (doxurrubicina, mitoxantrona, dactinomicina); Inibidores mitóticos (vincristina, vimblastina, paclitaxel), compostos platinados (cisplatina, carboplatina), outros compostos (L-asparaginase, hidroxiureia, prednisona/prednisolona, piroxicam) (Silveira, 2016). O fármaco citostático mais comumente utilizado na quimioterapia metronômica é a ciclofosfamida, mas existem vários outros estudos que mostram o uso de outros fármacos citostáticos, tais como clorambucil, lomustina, metrotexato, entre outros (Barros and Repetti, 2015). Além dos fármacos citostáticos clássicos também têm sido usado outros fármacos nos protocolos. Dentre eles estão os anti-inflamatórios não esteroides (AINES), antivasculares direcionados, como anticorpos monoclonais e inibidores do receptor de tirosina quinase (Barros and Repetti, 2015).

Ciclofosfamida e clorambucil são quimioterápicas com baixos níveis de toxicidade em doses metronômicas. A ciclofosfamida a baixas doses pode induzir cistite hemorrágica em $22 \%$ dos casos, quando usada a $25 \mathrm{mg} / \mathrm{m}^{2}$, quando usado a 10 e $15 \mathrm{mg} / \mathrm{m}^{2}$ o porcentual cai para $10 \%$ (Barros and Repetti, 2015). A ciclofosfamida é um agente aquilante derivado da mostarda nitrogenada que altera o DNA e é utilizado em protocolos combinados para linfomas, carcinomas e sarcomas. Pode ser administrado por via oral ou intravenosa e a sua dose varia de $50-250 \mathrm{mg} / \mathrm{m}^{2}$ (Khosravi and Pérez, 2007, Faro et al., 2009). Seus principais efeitos secundários são a supressão da medula óssea, efeitos gastrointestinais e a cistite hemorrágica estéril, que pode surgir devido a uma irrigação na bexiga causada pela acroleína, uma substancia que é causada pelo metabolismo da ciclofosfamida (Khosravi and Pérez, 2007). Dosagem metronômica varia de $10-15 \mathrm{mg} / \mathrm{m}^{2}$, o seu uso mostrou provocar efeitos antiangiogénicos e imunomodeladores, tanto usado sozinha quanto associada com outros agentes (Khosravi and Pérez, 2007).

Os anti-inflamatórios não esteroidais (AINES) tem função de bloquear as enzimas $\operatorname{COX} 1$ e 2 
reduzindo a síntese de prostaglandinas, assim combatendo a inflamação. Para o tratamento oncológico, os AINES têm importante ação antineoplásica, expressando a COX 2 e/ou PGE2, numa variedade considerável de tumores epiteliais e não epiteliais, incluindo carcinomas, osteossarcomas, melanoma oral e adenocarcinoma colorrectal (Silva et al., 2004, Khosravi and Pérez, 2007, Mendes, 2014). Não se sabe exatamente o porquê de alguns AINES terem uma ação antitumoral. Acredita-se que o motivo mais coerente seria baseado na demonstração de que a COX-2, e as PGs resultantes, possuem maior expressão em certos tecidos pré-malignos, contribuindo para a carcinogênese (Silva et al., 2004). Os AINES mais comumente usados são o piroxicam, carprofeno e meloxicam (Khosravi and Pérez, 2007). Efeitos colaterais que eles podem causar são irritações gastrointestinais e toxicidade hepática ou renal por diminuição da perfusão renal. Com exames complementares é possível identificar e controlar esses problemas (Antunes et al., 2008, Khosravi and Pérez, 2007).

\section{Material e Métodos}

Trata-se de um relato de caso, com dados da avaliação clínica, exames e descrição do tratamento clínico utilizado durante o atendimento realizado na Clínica Veterinária.

Um felino macho, castrado, sem raça definida, com $4 \mathrm{~kg}$ de massa corporal, 0,252 $\mathrm{m}^{2}$ de superfície corporal, com idade de três anos aproximadamente, foi atendido na Clínica Veterinária Dr. Alexandre, na cidade de Cascavel, Paraná, com relato de retenção e incontinência urinária. $\mathrm{O}$ exame físico revelou os valores de temperatura retal, frequência cardíaca e respiratória dentro da normalidade para a espécie. Observou-se, durante a palpação abdominal, que o paciente apresentava a bexiga aumentada devido a retenção de urina, além de dores devido ao ocorrido. Inicialmente foi o paciente foi medicado com analgésicos e relaxantes musculares e mantido em observação para ver se conseguiria urinar, após falha com os medicamentos foi realizado sonda uretral Tom Cat para retirar toda a urina e lavar a bexiga para retirar os sedimentos, já pensando, possivelmente, em um diagnóstico de cálculos que estariam inflamando a bexiga e/ou obstruindo a passagem da urina. Para ser possível a passagem da sonda, o animal foi sedado apenas utilizando o propofol na dosagem de $4 \mathrm{mg} / \mathrm{kg}$. Após três dias o animal voltou para a clínica com queixas de anuria. Durante o exame físico foi constatado que o animal estava novamente com retenção e incontinência urinária. Ele foi novamente passado por todo o procedimento anterior para aliviar a bexiga e ter tempo para marcar um exame de ultrassonografia, pois o segundo atendimento se passou num domingo, o animal ficou internado na clínica até marcar o exame. Durante o exame de ultrassonografia (US) foi observado uma massa na bexiga, mais especificamente na região de trigono vesical (Figura 1). Todos os outros órgãos avaliados apresentavam-se anatomicamente dentro dos parâmetros, sem nenhuma alteração visível.

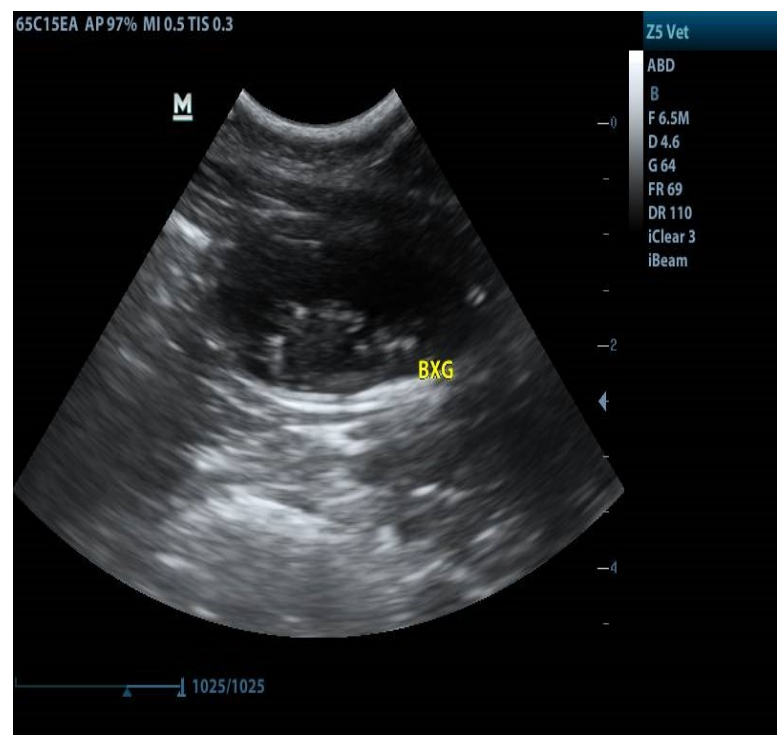

Figura 1. Exame de ultrassonografia mostrando a bexiga e um aumento de massa na região de trígono vesical, durante o primeiro mês de tratamento. Fonte: Grapegia and Lima (2017).

Com o resultado do exame de imagem, foi recomendado ao proprietário para fazer um exame citopatológico utilizando a urina do paciente; assim que aprovado, foi coletada a urina por uma cistocentese e mandado para o laboratório. Para o exame foi recebido $2,0 \mathrm{ml}$ de líquido marrom, onde foram depositados em tubos de ensaio e centrifugado a $1500 \mathrm{rpm}$ durante 7 minutos. Foi então espalhado em 2 lâminas de maneiras a se díspar em camada fina e única e fixadas em álcool $95 \%$. Na análise microscópica foi deparado com presença de células polimorfonucleares, com predomínio de neutrófilos lisados. Associado às células inflamatórias observam-se múltiplos agrupamentos de células epiteliais pleomórficas com anisocitose e anisocariose moderada. A conclusão do exame foi indicativa de células carcinomatosas e recomendado a retirada cirúrgica dos nódulos para análise histopatológica. 
Recomendou-se ao proprietário a não realização da cirurgia para análise histopatológica do tumor e tentar tratar com quimioterapia metronômica ao invés da quimioterapia convencional, por acreditar que com esse tratamento o animal terá efeitos colaterais pequenos ou nulos e também por ser um tratamento menos nocivo.

Os medicamentos usados para o tratamento foram a ciclofosfamida $3,6 \mathrm{mg} / \mathrm{m}^{2}$, como quimioterápico, piroxicam $0,3 \mathrm{mg} / \mathrm{kg}$, como AINE, e doxiciclina $5 \mathrm{mg} / \mathrm{kg}$, como antibiótico para prevenir uma possível erliquiose. Inicialmente a doxiciclina foi administrada todos os dias, e os outros dois medicamentos em dias alternados, após um mês com outro US realizado e apresentando uma melhora de mais de $80 \%$, mudou-se o tratamento; as doses foram ajustadas e o os três fármacos passaram a ser administrados diariamente. Houve a necessidade de tratamento de suporte com ranitidina $2,5 \mathrm{mg} / \mathrm{kg}$. Recomendou-se o acompanhamento com o US a cada 20 dias e os exames de sanguíneos a cada 30 a 60 dias.

\section{Resultados}

$\mathrm{O}$ tratamento iniciou-se com a ciclofosfamida $3,6 \mathrm{mg} / \mathrm{m}^{2}$ (SID), piroxicam $0,3 \mathrm{mg} / \mathrm{kg}$ (SID) e doxiciclina $5 \mathrm{mg} / \mathrm{kg}$ (BID). O quimioterápico e o anti-inflamatório eram administrados por via oral em dias alternados, enquanto o antibiótico o paciente recebia por via oral todos os dias. Esse protocolo foi usado durante as três primeiras semanas após o primeiro exame de ultrassom. Durante o segundo US (Figura 2) foi reparado uma melhora no tumor significativamente, tendo uma diminuição do tamanho de mais de $80 \%$. A partir disso, foram realizados ajustes nas doses dos fármacos de acordo com o peso do paciente; também passou a fornecer os três medicamentos todos os dias. Como o paciente apresentou êmese, foi necessário um tratamento de suporte, com ranitidina a $2,5 \mathrm{mg} / \mathrm{kg}$.

O paciente era acompanhado periodicamente, no mínimo uma vez ao mês para realização de exames ultrassonográfico e sanguíneos. Dentre todos os exames sanguíneos analisado, poucos tiveram alterações. O primeiro exame, que serviu de base para os outros, mostrou que o paciente apresentava certo nível de desidratação e uremia discreta. Esses resultados se mantiverem durante meses com o animal conseguindo viver tranquilamente sem estresse e dor. Os primeiros sinais de mudança no quadro clínico foram aparecer no quinto mês de tratamento, com um aumento de volume na massa tumoral e apresentando os linfonodos abdominais reativos (Figura 3).

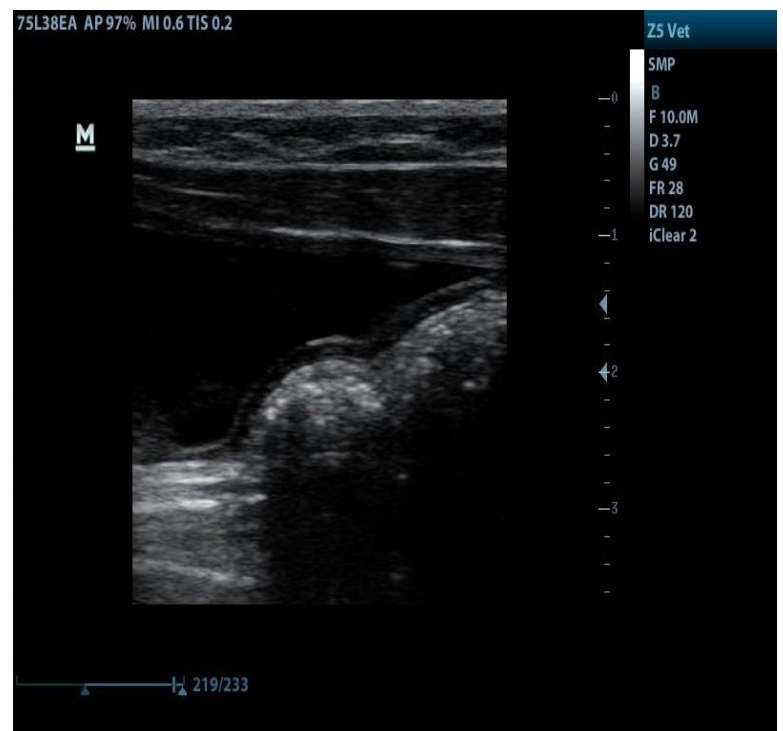

Figura 2. Exame de ultrassonografia mostrando bexiga e já diminuição da massa apresentada na região de trígono vesical, durante o segundo mês de tratamento. Fonte: Grapegia and Lima (2017).

Paciente apresentou leucopenia, concentração sérica de $3960 \mathrm{~mm}^{3}$, aspartato aminotransferase apresentou 146,19 U/L e alanine aminotransferase 408,01 U/L. Para a correção dessas alterações foi reduzido à metade da dose diária do quimioterápico e observado se o animal apresentaria melhora, e assim ocorrendo após 15 dias.

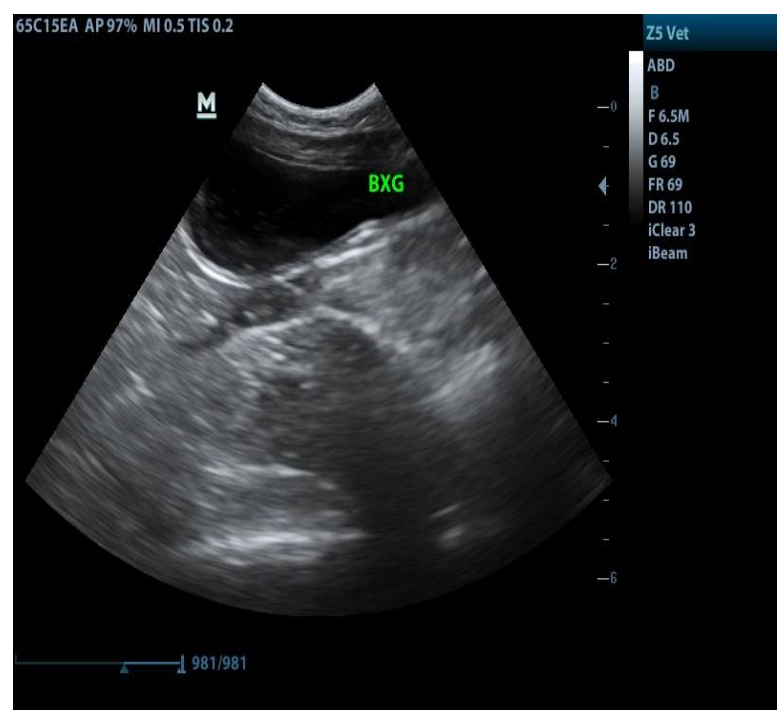

Figura 3. Exame de ultrassonografia mostrando bexiga e aumento de massa na região de trígono vesical, durante o quinto mês de tratamento. Fonte: Grapegia and Lima (2017). 
No sexto mês de tratamento, o exame de imagem (Figura 4) mostrou um aumento na massa tumoral, mas o quadro clínico do paciente apresentava-se estável.

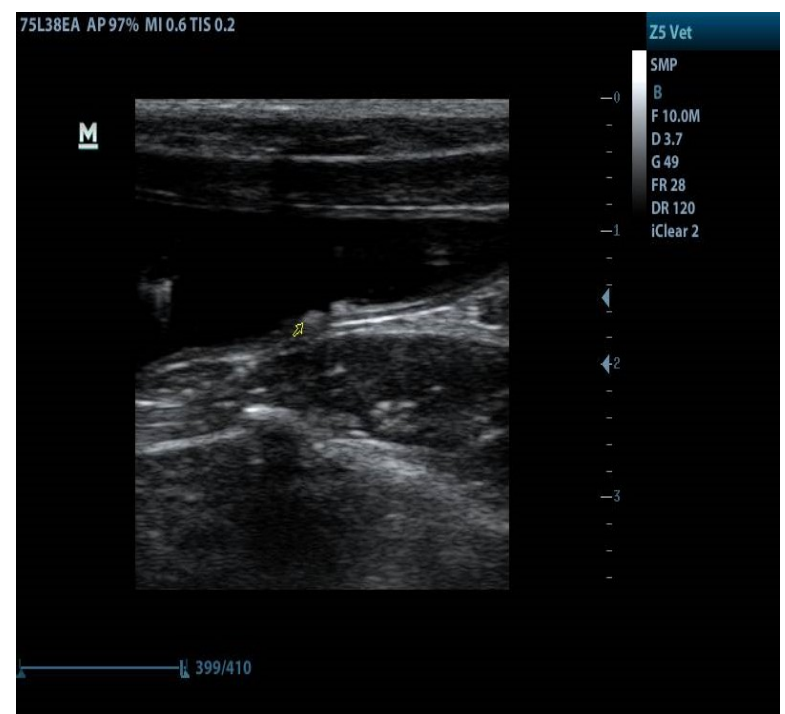

Figura 4. Exame de ultrassonografia mostrando bexiga aumento de massa na região de trígono vesical, durante o sexto mês de tratamento. Fonte: Grapegia and Lima (2017).

Durante os seis meses de tratamento, os resultados observados foram satisfatórios, controlando o crescimento da neoplasia e dos sinais clínicos, na região de trígono vesical.

\section{Discussão}

O diagnóstico de tumores vesicais na medicina veterinária é comum ser diagnosticado tardiamente, pois os sinais clínicos apresentados são facilmente confundidos com cistite inflamatórias-infecciosas. Assim podendo agravar a doença e acabar sendo descoberta em momentos em que o tumor está avançado (Froes et al., 2007).

$\mathrm{O}$ animal utilizado para o relato de caso não teve um diagnóstico tardio do tumor em trígono, mas teve uma evolução muito rápida do quadro clinico. De acordo com Martin, 2014, os sinais clínicos possíveis de serem apresentados são, disúria, polaquiúria, hematúria e anúria. $\mathrm{O}$ paciente apresentou disúria, polaquiúria, algumas vezes hematúria e até chegando a um quadro de anúria.

Para se ter um diagnóstico mais específico foi solicitado um ultrassom, o qual é o método de diagnóstico mais utilizado para a identificação de possíveis neoplasias de paciente com sinais clínicos de hematúria, disúria, polaquiúria e cistites infecciosas recorrentes. Durante o exame é possível ter uma boa avaliação do conteúdo luminal e da parede da bexiga (Froes et al., 2007). Com a descoberta de uma massa tumoral na bexiga, o passo seguinte é a realização de um exame citopatológico a partir da urina coletada por cateterização. Ao utilizar o processo de cateterização sempre se deve tomar o cuidado para não perfurar a parede da bexiga e também se deve ter os cuidados com higiene e antissepsia para não ocorrer uma infecção (Withrow et al., 2014).

Com a amostra de urina coletada o passo seguinte foi encaminhar à análise de citologia, e de acordo com Martin, 2014, 30\% das células neoplásicas estão presentes na urina, muitas vezes são indistinguíveis das células epiteliais reativas por causa da inflamação que está ocorrendo na bexiga. Na medicina veterinária, essa análise tem resultados de sensibilidade de $90 \%$ e de especificidade de $88 \%$, mas para que obter os resultados é necessário à amostra passar por uma centrifugação primeiro.

$\mathrm{O}$ resultado demonstrou células carcinomatosas de transição, onde segundo Crivellentin and Borin-Crivelletin (2015), carcinoma de células transicional é a neoplasia mais frequente na bexiga, podendo estar localizada na bexiga, uretra, ureter, próstata ou vagina. Quando presente na bexiga, a principal região acometida é de trígono vesical. Com o resultado da citologia começou-se o tratamento com a ciclofosfamida $3,6 \mathrm{mg} / \mathrm{m}^{2}$ (SID), piroxicam $0,3 \mathrm{mg} / \mathrm{kg}$ (SID) e doxiciclina $5 \mathrm{mg} / \mathrm{kg}$ (BID). A doxiciclina atuando como protocolo para tratamentos antitumorais tem função na inibição da neovascularização e também do crescimento do tumor (He and Marneros, 2014). A COX-2 está diretamente ligada a superprodução de prostaglandinas e o processo de carcinogênese nas células tumorais, como também a inibindo a apoptose, indução da angiogênese, estímulo da proliferação celular e o aumento da capacidade de invasão tumoral (Jark et al., 2011). A escolha do uso do piroxicam foi devido ele apresentar propriedades inibidoras do COX-2, por ser uma anti-inflamatório não esteroidal e também por ser possível o uso prolongado (Dória et al., 2012).

A escolha da ciclofosfamida se levou pelo fato desse quimioterápico apresentar qualidades de causar apoptose celular e impedir a formação de novos microvasos tumorais (García et al., 2009).

Os exames de ultrassonográfias eram realizados mensalmente para acompanhar a evolução do tratamento e se os outros órgãos não estavam sendo acometidos por uma possível 
metástase. Em um dos exames foi encontrado uma linfonodomegalia, suspeitando de uma metástase, mas sendo descartado após o outro exame de imagem mostrar que os linfonodos estavam normais. Para Thrall (2013) os exames de ultrassom são de extremamente importância para o acompanhamento de CCT e também dos outros órgãos para a procura de metástase.

Os exames sanguíneos eram realizados mensalmente para saber se o estado geral do paciente era apto para seguir com o tratamento. $\mathrm{Na}$ análise sanguínea se o felino apresentar concentrações séricas de leucócitos e plaquetas em níveis baixos o tratamento deve ser suspenso, adiado ou ajustado (Bado, 2011). No início as principais alterações mostradas nos exames sanguíneos era uremia e hematócrito baixo. O motivo que gerou essa uremia foi o fato do animal apresentar uma obstrução na bexiga, consequentemente não conseguindo urinar, assim ocorrendo pressão na capsula de Bowman e superando a pressão da artéria aferente, devido a vasoconstrição, isso levando a uma deficiência na filtração glomerular e não conseguindo excretar a ureia e portanto gerando a uremia (Nelson and Couto, 2015). A concentração sérica de hematócrito baixo é devido à falta de ingestão de água levando o animal a desidratação (Fossum, 2014, Nelson and Couto, 2015). As alterações em leucograma e bioquímicos se deram devido a toxicidade dos medicamentos usados e sendo corrigidos devido aos ajustes nas doses para continuação tratamento. Tratamentos quimioterápicos, seja metronomica ou dose máxima total, levam ao animal vários efeitos colaterais, como leucopenia e concentrações baixas de FA, ALT e AST, fora os distúrbios gastrointestinais (Cunha, 2014).

\section{Conclusões}

A quimioterapia metronômica é um tratamento onde $\mathrm{o}$ paciente recebe $\mathrm{o}$ quimioterápico diariamente e tem uma maior tolerância dos efeitos secundários, mas tendo uma desvantagem sobre o tratamento convencional devido ao tempo de redução da doença ser menor.

Devido os efeitos adversos da quimioterapia por dose máxima tolerada, a escolha pela quimioterapia metronômica ocorreu no intuito de reduzir os efeitos secundários que poderiam debilitar o animal, colocando a saúde do paciente em risco.
O tratamento com a quimioterapia metronômica no caso relatado foi satisfatório devido ao controle no crescimento da massa tumoral, na região de trígono vesical, apresentar redução e melhora no quadro clinico. A duração do tratamento foi de seis meses e durante esse período o paciente, no geral, apresentou melhora; entretanto ocorreram episódios em que o animal demonstrou alterações clinicas, as quais foram facilmente controladas.

Mesmo com o paciente apresentando ausência de sinais clínicos, o tumor continua presente na sua bexiga, mas está controlando devido as medicações e assim sendo possível ter uma alta qualidade e expectativa de vida.

Os resultados apresentados com o protocolo utilizado foram além das expectativas; porém não há previsão de até quando o tumor ira apresentarse controlado.

\section{Referências Bibliográficas}

Antunes, M. I. P. P., Moreno, K. \& Grumadas, C. E. S. 2008. Avaliação e manejo da dor em cães e gatos com câncer-revisão. Arquivos de Ciências Veterinárias e Zoologia da UNIPAR, 11, 113-119.

Bado, A. S. 2011. Linfoma alimentar em gatos. Medicina Veterinária. Universidade Federal do Rio Grande do Sul, Por to Alegre.

Barros, V. T. M. \& Repetti, C. S. F. 2015. Quimioterapia metronômica em cães: revisão de literatura Metronomic chemotherapy in dogs: a review. Revista Portuguesa de Ciência Veterinárias, 110, 593-594.

Cabral, A. S. R. M. 2013. Depuração plasmática de creatinina exógena em cães submetidos a protocolos terapêuticos de quimioterapia. Medicina Veterinária. Universidade de Lisboa. Faculdade de Medicina Veterinária, Lisboa.

Crivellentin, L. Z. \& Borin-Crivelletin, S. 2015. Casos de rotina em medicina veterinária de pequenos animais, São Paulo.

Cunha, E. S. G. 2014. Avaliação dos efeitos secundários dos fármacos quimioterápicos em animais de companhia: estudo retrospetivo. Faculdade de Medicina Vetrinária. Universidade de Lisboa, Lisboa.

Dória, R. G. S., Laskoski, L. M., Carvalho, M. B., Freitas, S. H. \& Pires, M. A. M. 2012. Uso de quimioterapia no tratamento de carcinoma de células escamosas com metástase em face de 
equino-relato de caso. Revista Brasileira de Medicina Veterinária, 34, 336-340.

Faro, A. M., Daleck, C. R., Santana, Á. E., Nardi, A. B., Motta, F. R. \& Eurides, D. 2009. Avaliação hematológica em cães submetidos ao tratamento quimioterápico com sulfato de vincristina, prednisona e ciclofosfamida. Estudo experimental. Ars Veterinaria, 24, 1-8.

Fossum, T. W. 2014. Cirurgia de pequenos animais, 4 edn. Elsevier Brasil, São Paulo.

Froes, T. R., Iwasaki, M., Campos, A. G., Torres, L. N. \& Dagli, M. L. Z. 2007. Avaliação ultrasonográfica e pelo Doppler colorido do carcinoma de células transicionais da bexiga em cães. Arquivo Brasileiro de Medicina Veterinaria e Zootecnia, 59, 1400-1407.

García, J. L., Pérez, M. L., González, G. J., Albuerne, N. B., Soto, M. V. L., Menéndez, M. R., Fernández, J. L. \& Viamontes, M. N. 2009. Quimioterapia metronómica con ciclofosfamida y metotrexato en pacientes con cáncer de mama metastásico en progresión. Revista Cubana de Medicina, 48, 1-14.

He, L. \& Marneros, A. G. 2014. Doxycycline inhibits polarization of macrophages to the proangiogenic M2-type and subsequent neovascularization. Journal of Biological Chemistry, 289, 8019-8028.

Jark, P. C., de Araújo Machado, L. H., Gomes Lourenço, M. L. \& Sakate, M. 2011. Uso de inibidores de COX-2 no tratamento do carcinoma de células de transição de bexiga em cães-revisão. Veterinária e Zootecnia, 18, 523-530.

Johnson, E. G. \& Wisner, E. R. 2007. Advances in respiratory imaging. Veterinary Clinics of North America: Small Animal Practice, 37, 879-900.

Khosravi, S. P. \& Pérez, M. G. 2007. Una nueva estrategia terapéutica en el cáncer de mama: quimioterapia metronómica. Anales de Medicina Interna. SciELO Espana.

Martins, D. B., Teixeira, L. V., França, R. T. \& Lopes, S. T. A. 2011. Biologia tumoral no cão: uma revisão. Medvep-Revista Científica de Medicina Veterinária, 9, 630-7.

Mendes, A. R. 2014. Avaliação da quimioterapia metronômica em carcinomas mamários de cadelas por imunomarcações. Faculdade de Medicina e Veterinária. Universidade Estadual de São Paulo, Araçatuba.
Nelson, R. W. \& Couto, C. G. 2015. Medicina interna de pequenos animais. Elsevier Editora, Amsterdan.

Osborne, C. A., Sanderson, S. L., Lulich, J. P., Bartges, J. W., Ulrich, L. K., Koehler, L. A., Bird, K. A. \& Swanson, L. L. 1999. Canine cystine urolithiasis: cause, detection, treatment, and prevention. Veterinary Clinics of North America: Small Animal Practice, 29, 193-211.

Pasquier, E., Kavallaris, M. \& André, N. 2010. Metronomic chemotherapy: new rationale for new directions. Nature Reviews Clinical Oncology, 7, 455-465.

Penter, C. D. 2013. Estudo retrospectivo da sobrevida de cães com osteossarcoma apendicular submetidos à amputação de membro com ou sem quimioterapia adjuvante. Faculdade de Medicina Veterinária. Universidade Federal do Rio Grande do Sul. , Porto Alegre.

Reis, D. S. 2010. Efeito de dose efetiva mínima e dose não tóxica de 5-Fluorouracil e Leucovorina sobre a atividade de células dendríticas humanas e sobre a imunogenicidade de células de câncer colorretal. Faculdade de Medicina. Universidade Estadual Paulista Júlio de Mesquita., Botucatu.

Silva, A. E., Serakides, R. \& Dantas Cassali, G. 2004. Carcinogênese hormonal e neoplasias hormônio-dependentes. Ciência Rural, 34, 625-633.

Silveira, P. S. D. 2016. Efeitos secundários da quimioterapia antineoplásica e seu impacto na qualidade de vida em cães e gatos com doença oncológica. Faculdade de Medicina Veterinária. Universidade de Lisboa, Lisboa.

Steffenon, S. M. 2014. Efeitos adversos do tratamento quimioterápico em cães e gatos com câncer. Medicina Veterinária. Universidade Federal do Rio Grande do Sul, Porto Alegre, Rio Grande do Sul.

Thrall, D. E. 2013. Textbook of veterinary diagnostic radiology. Elsevier Health Sciences, Philadelphia.

Withrow, S. J., Page, R. \& Vail, D. M. 2014. Withrow and MacEwen's small animal clinical oncology. Elsevier Health Sciences, St. Louis.

Article History:

Received 7 April 2017

Accepted 10 May 20177

Available on line 29 June 2017

License information: This is an open-access article distributed under the terms of the Creative Commons Attribution License 4.0, which permits unrestricted use, distribution, and reproduction in any medium, provided the original work is properly cited. 